\title{
Calidad sanitaria del agua de la ciénaga Mata de Palma en el Departamento del Cesar, Colombia
}

\author{
Sara Lilia Ávila de Navia', Sandra Mónica Estupiñán Torres ${ }^{1}$
}

1. Docentes Universidad Colegio Mayor de Cundinamarca, Bogotá, Colombia.

Correspondencia: slavila@unicolmayor.edu.co

Recibido: 22-01-09 / Aceptado: 27-02-09

\begin{abstract}
Resumen
La ciénaga Mata de Palma, ubicada en el departamento del Cesar, Colombia, está siendo afectada por las diferentes actividades productivas que se realizan en la zona, lo que ha alterado la función del ecosistema. Este humedal presenta agotamiento y degradación debido a la deforestación, a la entrada de aguas residuales, a la modificación de los regímenes hidráulicos y al uso de métodos inadecuados de explotación de peces, que agotan los recursos naturales y causan pobreza en la población.

Cuando se utiliza como medio de eliminación de excretas y otros desechos orgánicos, el agua es una fuente de transmisión de numerosos microorganismos, entre los que prevalecen los de origen intestinal. Es por esta razón que el control sanitario se realiza en función de la presencia de los coliformes totales, coliformes fecales y Enterococcus. Desde el punto de vista microbiológico, el examen de la calidad sanitaria del agua tiene por objetivo determinar la presencia de ciertos grupos de bacterias, que revelen una contaminación por materia fecal o por materia orgánica. Los recuentos de los indicadores de contaminación fecal mostraron que el agua no es apta para el consumo humano ni para uso recreativo. En esta ciénaga se identificaron una gran variedad de microorganismos que muestran la diversidad bacteriana que puede ser utilizada en biotecnología y en la indicación biológica, y de interés sanitario, pues afectan la salud humana y la de otros organismos.
\end{abstract}

Palabras clave: coliformes fecales, coliformes totales, Enterococcus, humedal, microbiología ambiental.

Abstract
Sanitary Water Quality from the Mata de Palma Wetland in the Department of Cesar, Colombia.
The Mata de Palma wetland, located in the department of Cesar, Colombia, is being affected by the different productive
activities that are performed in the area, which has altered ecosystem function. This represents wetland depletion and
degradation due to deforestation, entry of waste water, changing water regimes and the use of inappropriate methods
of exploitation of fish, which deplete natural resources, causing poverty in the population.
When used as a means of disposal of excreta and other organic wastes, water is a source of transmission of many
microorganisms, prevailing those of intestinal origin. It is for this reason that health checks are done based on the
presence of total coliform, fecal coliform and Enterococcus. From the microbiological point of view, consideration
of the sanitary quality of water is designed to determine the presence of certain groups of bacteria, which are
indicative of fecal contamination or organic matter. The counts of faecal pollution indicators showed that the water
is unfit for human consumption or for recreational use. In this swamp were identified a variety of microorganisms
that show bacterial diversity, which can be used in biotechnology and biological indication and medical interest,
as they affect human health and other organisms.

Keywords: Enterococcus, environmental microbiology, fecal coliforms, total coliforms, wetland. 


\section{Introducción}

El agua, además de ser una sustancia imprescindible para la vida, por sus múltiples propiedades, es ampliamente utilizada en actividades diarias tales como la agricultura (70\% al $80 \%)$, la industria (20\%), el uso doméstico $(6 \%)$, entre otras, convirtiéndose en uno de los recursos más apreciados en el planeta. De ahí la importancia de conservar y mantener la calidad de las fuentes naturales, de manera que se garantice su sostenibilidad y aprovechamiento para las futuras generaciones (1).

La eutrofización es un proceso natural en los ecosistemas acuáticos, producido por el enriquecimiento del cuerpo de agua con nutrientes (2). Durante los últimos 200 años el hombre ha acelerado este proceso modificando tanto la calidad de las aguas, como la estructura de las comunidades biológicas debido al aumento en la carga orgánica e inorgánica de los cuerpos de agua (3). La eutrofización reduce considerablemente los usos potenciales que tienen los recursos hídricos, puesto que induce a la mortalidad de especies animales, a la descomposición del agua y al crecimiento de microorganismos como bacterias, entre otros (2). Además, en muchas ocasiones los microorganismos se convierten en un riesgo para la salud humana, como es el caso de los agentes patógenos transmitidos por el agua, que constituyen un problema mundial (4).

La contaminación fecal de las aguas superficiales, que sirven como fuente de abastecimiento, es uno de los problemas más preocupantes en los países en vías de desarrollo. Esta contaminación se debe al vertimiento de los desagües sin ningún tratamiento, hecho que es usual en las grandes ciudades. En las zonas rurales la contaminación se origina en la defecación a campo abierto, en la presencia de animales domésticos y silvestres que actúan como reservorios de agentes patógenos.

Los agentes patógenos implicados en la transmisión hídrica de enfermedades son las bacterias, virus, protozoos, helmintos y cianobacterias. Estos microorganismos pueden causar enfermedades con diferentes niveles de gravedad, desde una gastroenteritis simple hasta cuadros graves de diarrea, disentería, fiebre tifoidea o hepatitis. La transmisión hídrica es sólo una de las vías, pues estos agentes patógenos también pueden ser transmitidos a través de alimentos, de persona a persona debido a malos hábitos higiénicos, de animales al hombre, entre otras rutas (5).

Determinar el tipo de microorganismos presentes en el agua y su concentración proporciona herramientas indispensables para conocer la calidad de la misma y para la toma de decisiones en relación al control de vertidos, tratamiento de aguas y conservación de ecosistemas, evitando así el riesgo de contaminación de las personas y el ambiente.

Las bacterias que se encuentran más frecuentemente en el agua son las bacterias entéricas que colonizan el tracto gastrointestinal del ser humano y son eliminadas a través de la materia fecal. Cuando estos microorganismos se introducen en el agua, las condiciones ambientales son muy diferentes y por lo tanto su capacidad de reproducirse y de sobrevivir son limitadas. Debido a que su detección y recuento a nivel de laboratorio son lentos y laboriosos, se ha usado el grupo de las bacterias coliformes como indicadores, ya que su detección es más rápida y fácil (6-9).

\section{Materiales y métodos}

\section{Área de estudio}

La ciénaga Mata de Palma está alimentada por los arroyos Paraluz y Garrapato, este último proveniente del área minera de la mina Pribbenow, propiedad de la Multinacional Drummond Corporation, en la población de La Loma de Calenturas en el departamento del Cesar, Colombia. La ciénaga actualmente presenta alta intervención antrópica, no sólo por la actividad minera que se ha desarrollado durante varias décadas, que afecta la calidad de algunos de sus afluentes, sino que se está viendo altamente intervenida por las poblaciones aledañas a la zona y por la explotación agropecuaria.

\section{Estaciones de muestreo}

Se tomaron en total 12 muestras de agua superficial en la Ciénaga Mata de Palma, para evaluar posibles variaciones temporales de la calidad microbiológica, se realizaron cuatro muestreos, dos en época de lluvias (octubre de 2006 y junio de 2007) y dos en época seca (febrero y agosto de 2007). Las coordenadas de los puntos de muestreo se encuentran en la Tabla 1. 
Tabla 1. Coordenadas de los puntos de muestreo Ciénaga Mata de Palma.

\begin{tabular}{|ccc|}
\hline Sitio & \multicolumn{2}{c|}{ Coordenadas } \\
\hline Mata de Palma 1 & $9^{\circ} 35^{\prime} 59,6^{\prime \prime}$ & W \\
Mata de Palma 2 & $9^{\circ} 38^{\prime} 43,3^{\prime \prime} 1^{\prime \prime}$ \\
Mata de Palma 3 & $9^{\circ}$ & $73^{\circ} 38^{\prime} 44,1^{\prime \prime}$ \\
& $9^{\circ} 33^{\prime} 8,8^{\prime \prime}$ & $73^{\circ} 38^{\prime} 48,3^{\prime \prime}$ \\
\hline
\end{tabular}

\section{Toma de muestras}

La obtención de las muestras se realizó teniendo en cuenta la guía para la toma de muestras de agua del Ministerio de Salud de Colombia (Decreto 475 de 1998) (10) y las recomendaciones de Andreu y Camacho (11).

\section{Procesamiento de las muestras}

La metodología empleada para el análisis de los grupos de microorganismos fue la recomendada por la EPA (Environmental Protection Agency) (12). La técnica utilizada para el análisis bacteriológico del agua fue la filtración por membrana. Los medios utilizados para la enumeración de las bacterias indicadoras de contaminación de aguas son: bacterias coliformes totales agar endo NPS, Escherichia coli agar M-FC y para Enterococcus agar azida NPS. La identificación de los microorganismos aislados se realizó mediante pruebas bioquímicas rápidas Crystal BBL, para Enterobacterias y bacterias Gram positivas.

\section{Resultados}

\section{Coliformes totales}

Se encontró un alto número de coliformes totales en los tres puntos muestreados, tanto en época de lluvia como en época seca, aunque los mayores recuentos fueron en la época de lluvia de junio de 2007. Sin embargo, el número de bacterias (UFC/100mL) en todos los puntos analizados exceden los valores permitidos en el decreto 1594/84 que reglamenta el uso del agua, y por lo tanto, el agua de la Ciénaga Mata de Palma no puede destinarse para consumo humano, ni agrícola ni recreativo, Tabla 2 y Figura 1.

\section{Coliformes fecales}

En general el recuento de estos microorganismos fue muy similar a los coliformes totales en la época de

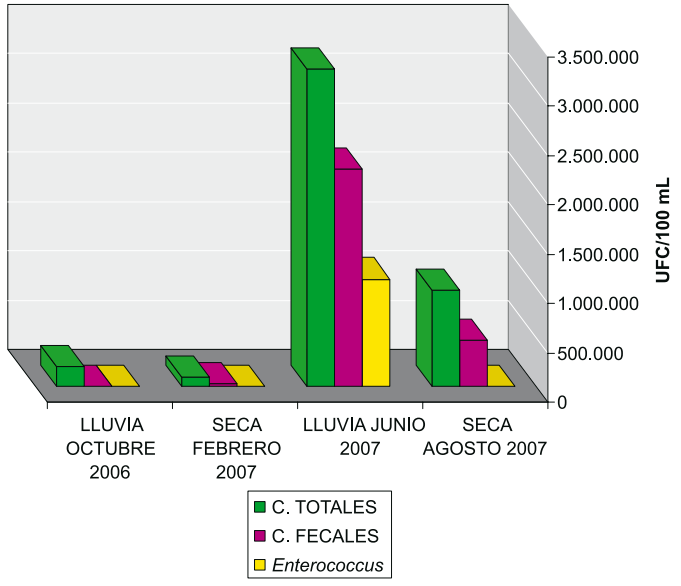

Figura 1. Promedio de recuentos bacterianos en UFC/100mL de los seis grupos bacterianos analizados para la Cienaga Mata de Palma del Cesar, Colombia.

lluvia de junio de 2007. En época de lluvia de octubre de 2006, no se encontraron recuentos de coliformes fecales, comportamiento similar se observó en el punto Mata de Palma 3 durante la época seca de febrero de 2007. El hecho de que en algunos puntos no se encontraran coliformes fecales a pesar de que existen recuentos de coliformes totales altos, puede ser debido a la menor resistencia de los coliformes fecales a las condiciones medioambientales, lo que hace que su recuperación en medios artificiales sea difícil, Tabla 2 y Figura 1.

Con base en la norma colombiana que reglamenta el uso del agua y los criterios de calidad para la destinación de este recurso (Decreto 1594/84), el agua no puede usarse para consumo humano ni para uso agrícola o recreativo.

\section{Enterococcus}

Este grupo incluye a especies tales como Enterococcus faecium y Enterococcus faecalis, que se encuentran en heces humanas y animales. Debido a su resistencia a los factores medioambientales tienen un mayor tiempo de supervivencia, por lo tanto, son considerados como 
Tabla 2. Recuentos bacteriológicos en UFC/100mL de los tres grupos bacterianos analizados para cada uno de los puntos de muestreo de la Cienaga Mata de Palma, Cesar, Colombia.

\begin{tabular}{|c|c|c|c|}
\hline \multicolumn{4}{|c|}{ Época Iluvia octubre 2006} \\
\hline & Mata de Palma 1 & Mata de Palma 2 & Mata de Palma 3 \\
\hline ormes totales & 200.000 & 200.000 & 200.000 \\
\hline ormes fecales & 0 & 0 & 0 \\
\hline iterococcus & 0 & 0 & 0 \\
\hline \multicolumn{4}{|c|}{ Época seca febrero 2007} \\
\hline & Mata de Palma 1 & Mata de Palma 2 & Mata de Palma 3 \\
\hline ormes totales & 56.000 & 112.000 & 112.000 \\
\hline ormes fecales & 10.800 & 71.600 & 0 \\
\hline iterococcus & 0 & 0 & 0 \\
\hline \multicolumn{4}{|c|}{ Época lluvia junio 2007} \\
\hline & Mata de Palma 1 & Mata de Palma 2 & Mata de Palma 3 \\
\hline ormes totales & 3.220 .000 & 3.220 .000 & 3.220 .000 \\
\hline ormes fecales & 3.220 .000 & 160.000 & 3.220 .000 \\
\hline iterococcus & 3.220 .000 & 32.000 & 16.000 \\
\hline \multicolumn{4}{|c|}{ Época seca agosto 2007} \\
\hline & Mata de Palma 1 & Mata de Palma 2 & Mata de Palma 3 \\
\hline ormes totales & 972.000 & 972.000 & 972.000 \\
\hline ormes fecales & 588.000 & 248.000 & 588.000 \\
\hline iterococcus & 0 & 0 & 0 \\
\hline
\end{tabular}

indicadores de contaminación fecal antigua en contraste con la presencia de coliformes fecales que indican la contaminación fecal reciente. Solamente se presentaron recuentos de Enterococcus en todos los puntos muestreados durante la época lluvia de junio de 2007, en los otros meses de muestreo no se encontraron Enterococcus en ninguno de los puntos, esto podría indicar que la contaminación fecal es más reciente, Tabla 2 y Figura 1.

\section{Discusión}

Se obtuvo un alto número de coliformes totales en todos los puntos muestreados, con base en la norma colombiana que reglamenta el uso del agua y los criterios de calidad para la destinación de este recurso (Decreto 1594/84), el agua de la ciénaga Mata de Palma no puede ser utilizada para uso agrícola ni para uso recreativo. Los recuentos fueron más altos en época lluvia, en especial en junio de 2007. Dentro de las patologías causadas por este grupo de bacterias coliformes se encuentran entre otras: síndrome urémico hemolítico, gastroenteritis e infecciones como: urinaria, del tracto respiratorio bajo, de piel y de tejidos blandos, intraabdominales y oftálmicas; intoxicación alimentaria, meningitis neonatal y septicemia (13).

El recuento de coliformes fecales es muy similar a los coliformes totales durante junio de 2007, sin embargo, en la época lluvia de octubre de 2006 no se encontraron recuentos de coliformes fecales en ninguno de los puntos muestreados. La presencia de coliformes en el agua indica la contaminación bacteriana reciente y constituye un indicador de degradación de los cuerpos de agua (6). Según la norma colombiana que reglamenta el uso del agua y los criterios de calidad para la destinación de este recurso (Decreto 1594/84), solamente el agua con recuentos de coliformes fecales inferiores a $1.000 \mathrm{UFC} / 100 \mathrm{~mL}$ podría ser utilizada para uso agrícola y con recuentos inferiores a $2.000 \mathrm{UFC/} 100 \mathrm{~mL}$ podría ser usada para uso humano después de tratamiento convencional. En la ciénaga Mata de Palma los valores encontrados exceden los permitidos por la norma.

Los coliformes fecales y Escherichia coli en particular, se han seleccionado como indicadores de contaminación fecal debido a su relación con el grupo tifoide-paratifoide 
y a su alta concentración en diferentes tipos de muestras. Aproximadamente el $95 \%$ del grupo de los coliformes presentes en heces fecales están formados por E. coli y ciertas especies de Klebsiella, ya que los coliformes fecales se encuentran casi exclusivamente en las heces de animales de sangre caliente, se considera que reflejan mejor la presencia de contaminación fecal.

Únicamente durante la época lluvia de junio de 2007 se presentaron recuentos de Enterococcus en todos los puntos muestreados, lo que podría indicar que la contaminación fecal es más frecuente en la época de lluvia y durante este período del año. Los Enterococcus fecales no se multiplican en el medio ambiente, o si esto ocurre es solamente en raras ocasiones, son más persistentes en ambientes acuáticos y en suelos contaminados que E. coli. Son importantes en situaciones donde se sabe que hay contaminación fecal y no se detectan coliformes, como ocurre cuando las descargas son intermitentes o más antiguas, de modo que mueren los coliformes totales y E. coli, y permanecen los Enterococcus (6).

La presencia de Enterococcus se ha asociado a contaminación fecal de origen humano y animal (5), se ha demostrado en algunos estudios que la presencia de animales puede afectar la calidad bacteriológica de las aguas (14). Los Enterococcus fecales han sido utilizados con los coliformes fecales para diferenciar la contaminación fecal del hombre de otros animales de sangre caliente. La razón entre coliformes fecales y Enterococcus fecales proveen información acerca de la fuente de contaminación. Un rango mayor de 4 es considerado indicativo de contaminación fecal humana, un rango menor a 0.7 sugiere contaminación por una fuente no humana (15).

Según lo anterior, podemos señalar que la fuente probable de contaminación en la ciénaga Mata de Palma es más de origen humano, sin embargo, como se mencionó anteriormente, los coliformes fecales presentan una baja supervivencia en ambientes acuáticos y requieren condiciones especiales para recuperarlos del estrés fisiológico, por lo tanto, no puede descartarse que la contaminación de estos cuerpos de agua también sea de origen animal, ya que en este lugar se observan gran cantidad de aves y se desarrollan actividades de ganadería en las fincas aledañas.

Las bacterias del tracto intestinal no suelen sobrevivir en el medio acuático, están sometidas a un estrés fisiológico y pierden gradualmente la capacidad de producir colonias en medios diferenciales y selectivos. Su velocidad de mortalidad depende de la temperatura del agua, de los efectos de la luz solar, de las poblaciones de otras bacterias presentes, y de la composición química del agua. Otro factor determinante para detectar la presencia de coliformes fecales en aguas es que los métodos deben ser más específicos que para coliformes totales, y de esta manera asegurar la resucitación del estrés fisiológico a que son sometidas las células bacterianas y en particular la $E$. coli.

En los pocos estudios en los que se ha examinado la eficacia de la recuperación de coliformes fecales en aguas tropicales, se encuentra una gran variedad de grado de recuperación, por lo tanto, estos sugieren que la $E$ coli podría no ser un indicador de contaminación fecal en aguas tropicales (16), lo anterior explica por qué en algunos puntos de la ciénaga Mata de Palma no se presentaron recuentos de coliformes fecales ni Enterococcus (6). No se encontró ninguna asociación entre las especies bacterianas aisladas en cada una de las estaciones, estas difieren durante todo el estudio, a continuación se presentan las características generales de las especies aisladas.

- Acinetobacter baumannii: está involucrado en diferentes procesos infecciosos en personas inmunosuprimidas (13).

- Acinetobacter iwoffi: produce infecciones del tracto respiratorio, urinario y de heridas, sepsis, abscesos y meningitis (13).

- Klebsiella pneumoniae y Klebsiella oxytoca: hacen parte de la flora intestinal humana y animal. Puede ser aislada de suelo y agua, causa infección nosocomial e infecciones adquiridas en la comunidad en humanos (13).

- Enterobacter cloacae: es la especie de Enterobacter más frecuentemente aislada en humanos y animales, es parte de la flora intestinal normal de animales y humanos y se ha aislado de suelo, agua, alimentos y medio hospitalario. Causa infecciones como meningitis, septicemia y abscesos especialmente en individuos inmunosuprimidos (13).

- Enterobacter sakazakii:se encuentra en el medioambiente y alimentos pero raramente se aísla de muestras clínicas. Causa meningitis neonatal y septicemia (13).

- Staphylococcus warneri: causa infecciones en pacientes inmunocomprometidos (17). 
- Staphylococcus aureus: es una bacteria que se encuentra en la piel y fosas nasales de las personas sanas, que causa gran variedad de infecciones, desde infecciones menores de la piel (forúnculos, ampollas, vejigas) y abscesos cutáneos hasta enfermedades que pueden poner en peligro la vida como neumonía, meningitis, endocarditis, síndrome del shock toxico y sepsis (17).

- Staphylococcus lugdunensis: patógeno con un importante potencial agresivo, causa infecciones especialmente de piel y tejidos blandos (13).

- Staphylococcus epidermidis: es flora normal de la piel y mucosas respiratorias humanas y animales, patógeno oportunista que causa infecciones del tracto urinario, de heridas, endocarditis y septicemia (13).

- Lactococcus lactis: es una especie de bacteria usada extensamente en la producción de manteca y queso (13).

- Lactococcus garvieae: es el mayor patógeno de peces, produce septicemia fatal entre especies de peces que viven en diferentes ambientes (18).

- Enterococcus durans: causa diarrea en humanos y animales (13).

- Serratia marcescens: produce olor a orina (trimetilamina) (19) produce fascitis necrotizante (20).

- Corynebacterium renale group: es productor de prostatitis ulcerativa en humanos y ovejas (21).

- Bacillus cereus: produce toxiinfecciones alimentarias (13).

- Flavobacterium odoratum: causa celulitis (22) y bacteremia (23).

- Flavimonas oryzihabitans: produce bacteremia, sinusitis, meningitis, endoftalmitis, empiema pleural (24).

- Stenotrophomonas maltophilia: su hábitat principal es el acuático, si bien se encuentra en el suelo, en las plantas y en los animales, actualmente se considera un patógeno nosocomial emergente (13).

- Pantoea agglomerans: patógeno de plantas y humanos (17).

- Leclercia adecarboxylata: pertenece a la familia Enterobacteriaceae, es una bacteria ubicua, se ha aislado en escasas ocasiones de una variedad de muestras clínicas como sangre, esputo, heridas, así como de comidas, agua y medio ambiente (25).

De acuerdo con los resultados obtenidos en el estudio, se recomienda implementar planes de monitoreo de la calidad sanitaria de las aguas de la ciénaga para llevar a cabo un control sobre el recurso y el nivel trófico de sus aguas.
Además, se hace necesario bajar la carga de nutrientes que llegan a la ciénaga procedentes de las diferentes actividades económicas desarrolladas en la zona, con el fin de controlar la multiplicación de los microorganismos patógenos y así disminuir el riesgo de enfermedades en la población aledaña a la ciénaga.

\section{Agradecimientos}

Las autoras expresan sus agradecimientos a la Universidad Colegio Mayor de Cundinamarca, al Doctor J. Orlando Rangel Ch., del Instituto de Ciencias Naturales de la Universidad Nacional de Colombia y a la Corporación Autónoma del Cesar - CORPOCESAR por su apoyo en el desarrollo de este trabajo. NO

\section{Referencias}

1. Organización de las Naciones Unidas (ONU), Departamento De Economía Y Asuntos Sociales: División para el Desarrollo Sostenible. 1992. Agenda 21. http://www.un.org/esa/sustdev/documents/agenda21/ spanish/agenda21spchapter18.htm.

2. Ramírez A, Viña G. Limnología colombiana: aportes a su conocimiento y estadísticas de análisis. Fundación Universidad Jorge Tadeo Lozano. Colombia 1998;293.

3. Burkholder J. Eutrophication and oligotrophication. En: ASHER S. Ed. Encyclopedia of biodiversity. United Status. Academic Press. 2001;2:649-670.

4. Vargas C, Rojas R, Joseli J. Control y Vigilancia de la Calidad del Agua de Consumo humano. Textos Completos. CEPIS. 1996;27.

5. Prescott L, J. Harley \& D. Klein. Microbiología. Editorial McGraw-Hill. Madrid, España. 1999.

6. Olivieri VP. Bacterial indicators of pollution. Ed. Wesley O. Pipes. Boca Raton, Florida. 1982;21-41.

7. Craun GF, Berger P, Calderon R. Coliform bacteria and waterborne disease outbreaks. J Am Water Works Assoc. 1997;89:96-104.

8. Rose JB. Environmental ecology of Cryptosporidium and public health implications. Ann Rev Publ Health. 1997;18:135-161.

9. Steiner TS, Thielman NM, Guerrant RL. Protozoal agents. What are the dangers for the public water-supply. Annu Rev Med. 1997;48:329-340.

10. Ministerio de Salud de Colombia. Guía para la toma de muestras. Decreto 475 de 1998.

11. Andreu E, Camacho A. Recomendaciones para la toma de muestras de agua, biota y sedimentos en humedales Ramsar. Ministerio del Medio Ambiente. Dirección General de Conservación de la Naturaleza. Secretaria General del Medio Ambiente. Madrid, España. 2002.

12. Environment Protection Agency. Standing Committee of Analysts, The Microbiology of Drinking Water - Part 1 - Water Quality and Public Health, Methods for the Examination of Waters and Associated Materials. Environment Agency. United States. 2002.

13. Brooks GF, Butel J, Morse S. Microbiologia médica de Jawetz, Melnick y Adelberg. Ed. Manual Moderno. 2005.

14. Namihira P, Barrera G, Márquez A. Contaminación por bacterias fecales en el Lago Huayamilpas, México D.F. Hidrobiológica. 2002;12:129-136. 
15. Espigares-García M. Virus en aguas de consumo. Hig. Sanid. Ambient. 2006;6:173-189.

16. Santiago-Mercado J, Hazent T. Comparison of Four Membrane Filter Methods for Fecal Coliform Enumeration in Tropical Waters. Appl Environ Microbiol.1987;53:2922-2928.

17. Koneman E, Allen S, Janda W, Schreckenberger P, Winn W. Diagnóstico microbiológico. Ed. Médica Panamericana. Bogotá.2003.

18. Eldar A, Goria M, Ghittino C, Zlotkin A, Bercovier H. Biodiversity of Lactococcus garvieae strains isolated from fish in Europe, Asia, and Australia. Appl Environ Microbiol. 1999;65:1005-1008.

19. Unemoto T, Hayashi M, Miyaki K, Hayashi M. Formation of trimethylamine from DL-carnitine by Serratia marcescens. Biochim Biophys Acta. 1966;121:220-222

20. Curtis CE, Chock S, Henderson T, Holman MJ. A fatal case of necrotizing fascitis caused by Serratia marcescens. Am Surg. 2005;71:228-230.
21. Loste A, Ramos JJ, García L, Ferrer LM, Verde MT. High Prevalence of Ulcerative Posthitis in Rasa Aragonesa Rams Associated with a Legumerich Diet. J Vet Med A Physiol Pathol Clin Med. 2005;52:176-179.

22. Bachman KH, Sewell DL, Strausbaugh LJ. Recurrent cellulitis and bacteremia caused by Flavobacterium odoratum. Clin Infect Dis. 1996;22:1112-1113.

23. Spanik S, Trupl J, Krcmery V. Nosocomial catheter-associated Flavobacterium odoratum bacteraemia in cancer patients. J Med Microbiol. 1998;47:183.

24. Qian K, Wang S. Infections caused by Flavimonas oryzihabitans. Chin Med J (Engl). 2001;114:394-398.

25. Campos M, Amuy E, Vargas A, Herrera M. Leclercia adecarboxylata Primer aislamiento reportado en Costa Rica. Rev Med Hosp Nac Niños Dr. Carlos Saenz Herrera. 2000;35:41-43. 